\title{
A função dos Tribunais Constitucionais para a Teoria dos Sistemas de Niklas Luhmann
}

(Trabalho originalmente apresentado como conclusão da disciplina Sociologia Jurídica no Programa de Pós-Graduação - Mestrado e Doutorado - da Faculdade de Direito da Universidade Federal de Minas Gerais.)

\author{
Autor: Flávio Quinaud Pedron \\ (Mestrando em Direito Constitucional na UFMG \\ Monitor de Pós-Graduação nas disciplinas Teoria da \\ Constituição e Teoria Geral do Direito Público \\ Bolsista pelo CNPq)
}

| Artigo publicado em 17.12.2004 |

Introdução. 1 - A teoria dos Sistemas de Niklas Luhmann: algumas aclarações conceituais. 2 - A função dos Tribunais Constitucionais no Sistema do Direito. 2.1 - O que é a constituição para a Teoria dos Sistemas? 2.2 - Mas, então, o tribunal constitucional guarda o quê? Conclusão. Referências bibliográficas.

\section{I ntrodução}

Tomando por base as transformações empreendidas pela modernidade, pode-se perceber que a sociedade atual mostra-se bem mais complexa que outrora. Em razão desse aumento de complexidade, diversos subsistemas surgem a partir de um processo de especificação e de diferenciação funcional, formando o que Niklas Luhmann denominará de subsistemas sociais, cuja característica primordial será o seu

fechamento operacional e sua, subseqüente, autonomia com relação aos outros subsistemas.

O direito, bem como a política, insere-se como um dentre outros subsistemas e, por isso mesmo, capaz de desenvolver códigos próprios para desempenharem suas funções recíprocas no interior da sociedade. O primeiro, como se verá, utilizando-se do código direito/não-direito, funciona para a estabilização de expectativas de comportamento, ao passo que o segundo, ao fazer uso do código governo/oposição, atua para condensar a formação das opiniões públicas de tal maneira que seja possível a tomada de decisões que vinculem coletivamente (LUHMANN, 2002:490).

É a partir de tais premissas que a Teoria dos Sistemas de Niklas Luhmann se desenvolve e ganha relevância. Através de um olhar bastante arguto, esta teoria mostra-se como um instrumental de vital importância para a autocompreensão do Direito. 
Sendo assim, o presente trabalho tem como objetivo utilizar os conteúdos teóricos da Teoria dos Sistemas para responder uma questão:

Como se pode compreender o papel desempenhado pelos assim chamados Tribunais Constitucionais dentro do Sistema do Direito?

Devido à própria complexidade da teoria luhmanniana, para que seja possível responder a questão proposta acima, primeiro, faz-se necessário delinear seus conceitos principais, sem a referência a um sistema social específico, demonstrando sua aplicabilidade para todos simultaneamente e, com isso, oferecendo uma visão mais panorâmica de tal pensamento.

Em segundo momento, adotar-se-á uma linha de raciocínio que busca responder ao problema proposto propriamente dito. Desta feita, fica reservado ao segundo ponto do trabalho, que começará com uma explicação e descrição sobre as características do Sistema do Direito e do Sistema da Política. Em seguida, tratar-se-á do aclaramento do que Luhmann compreende como Constituição, uma que esta é tida pelas teorias clássicas como o objeto da jurisdição constitucional, que seria, então, exercida, em sua modalidade concentrada, pelos Tribunais Constitucionais. Mas será realmente isso?

Partindo dessa dúvida, verificar-se-á se o Tribunal Constitucional representa para a Teoria dos Sistemas a figura de um "guardião" da Constituição, como ficou fixado através do notório debate sobre o tema travado entre Hans Kelsen e Carl Schmitt. Será, portanto, necessário reconstruir parte de tais argumentos para, ao confrontálos, tornar mais clara a concepção luhmanniana de Constituição e da atividade dos Tribunais para o Sistema do Direito.

1 - A Teoria dos Sistemas de Niklas Luhmann: algumas aclarações conceituais

Como demonstrado por Juliana Neuenschwander Magalhães (2004), a entrada para a modernidade (1), principalmente a partir do desenvolvimento da concepção de indivíduo, marca um período de incremento de complexidade sem precedentes. Assim,

"o que conhecemos com o nome de modernidade começa quando desaparece a idéia de uma ordem universal - seja ela imanente ao cosmos ou transcendente a ele. Em outras palavras, a modernidade começa quando termina a idéia de "mundo" (espaço infinito, dotado de centro e de periferia e de "lugares" naturais) e de hierarquia natural dos seres, cedendo para as idéias de universo infinito, desprovido de centro e de periferia, e de indivíduo livre, átomo no interior da Natureza e para o qual já não possuímos a definição 
prévia de seu lugar próprio e, portanto, de suas virtudes políticas. (...) A modernidade afasta a idéia (medieval e renascentista) de um universo regido por forças espirituais secretas que precisavam ser decifradas para que com elas entremos em comunhão. $O$ mundo se desencanta - como escreveu Weber - e passa a ser governado por leis naturais racionais e impessoais que podem ser conhecidas por nossa razão e que permitirão aos homens o domínio sobre a Natureza". (CHAUí, 1992:350).

É por isso que, na Antigüidade Clássica, poderia ser observada uma distinção entre gregos, de um lado, e bárbaros,(2) de outro, que funcionava como critério único de separação e que, ao mesmo tempo, sintetizava todos os reflexos produzidos no contexto social, político, econômico, jurídico e cultural da época. Já, na modernidade, a figura do indivíduo traz em si uma complexidade muito maior. Inexiste o referencial único, pois, se for tomada a distinção entre católico e pagão, esta já se mostra insuficiente devido ao universo de particularidades englobadas pela classificação de (pagão) não-católico - a exemplo, temos, hoje, toda uma constelação de doutrinas surgida no movimento da reforma protesta (luteranos, anglicanos, calvinistas), além de agnósticos, espíritas, budistas, etc. Também é insuficiente a separação nobre e plebeu, já vista toda a mudança e perda dos estratos sociais que eram estanque na I dade Média. Assim, para usar uma expressão do sociólogo polonês Zygmunt Bauman (2001), estamos no tempo da liquidez.(3)

É por isso que aliado a esse aumento de complexidade, pode ser observado um processo de diferenciação funcional da sociedade, que passou a reagir de modo diverso aos diferentes estímulos existentes.

É por isso que o pensamento de Niklas Luhmann ganha relevo, já que "La complejidad, que en la perspectiva luhmanniana no es vista como un obstáculo ni una dificultad para la construcción de un sistema, se constituye en la condición que hace posible al sistema. Un sistema surge en un proceso de reducción de complejidad. Es menos complejo que su entorno y sus limites respecto de él no son físicos, sino de sentido". (ÁLVAREZ, 2003:278)(4)

Através de um olhar sociológico(5), Luhmann desenvolve sua Teoria dos Sistemas e da Sociedade, que compreende os diferentes tipos de sistemas, bem como as condições distintivas, a partir da complexidade que se tenta reduzir. Apresenta-se como um poderoso instrumental analítico que permite a compreensão do funcionamento da sociedade(6) e de seus subsistemas - direito, política, economia, religião, entre outros - cada qual operando por meio de um código próprio, o que permite sua identificação e separação, bem como a 
conseqüente redução de complexidade, já que o sistema é sempre menos complexo que seu ambiente.

É por isso, mesmo, que a teoria dos sistemas começa com uma afirmação, dirá Álvarez (2003: 281): os sistemas existem!

Conforme Luhmann,

"se puede hablar de sistema cuando se tiene ante los ojos características que, si se suprimieran, podrían en cuestión el carácter de objeto de dicho sistema. A veces, también se llama sistema al conjunto de dichas características. En el mismo sentido entonces: La afirmación "hay sistemas" solo quiera decir que hay objetos de investigación con tales características que justifican el empleo Del concepto de sistema. Así como al contrario: el concepto de sistema nos sirve para abstraer hechos que son comparables entre si, o hechos de carácter distinto bajo el aspecto igual/desigual". (LUHMANN apud ÁLVAREZ, 2003:281)

Sistema é, então, um "conjunto de elementos inter-relacionados, cuja unidade é dada por suas interações e cujas propriedades são distintas da soma desses elementos" (CHAl, 2004:50). Assim, a teoria dos sistemas começa a ser construída pela distinção feita entre sistema e ambiente. É a identificação de uma igualdade em uma diferença que projeta a distinção entre sistema e ambiente (ÁLVAREZ, 2003: 281), deste modo, o sistema se constitui e se conserva mediante a criação e recriação dessa diferença.

Tal processo permite ao sistema desenvolver o que Luhmann vai chamar de autoreferência, isto é, "capacidade de estabelecer aquelas relações entre si ao mesmo tempo em que diferenciam essas relações das relações mantidas com seu ambiente" (CHAI, 2004:50)(7), e que permitem o fechamento operacional do mesmo sistema.

"Por operativamente clausurados deben definirse los sistemas que, para la producción de sus propias operaciones, se remiten a la red de sus propias operaciones y en este sentido se reproducen a si mismos. Con una formulación un poco más libre se podría decir: el sistema debe presuponerse a si mismo, para poner en marcha mediante operaciones suyas su propia reproducción en el tiempo; o con otra palabras: el sistema produce operaciones propias anticipando y recurriendo a operaciones propias $\mathrm{y}$, de esta manera, determina qué es lo que pertenece al sistema y qué al entorno". (LUHMANN, 2002: 99-100)

Cabe, então, aclarar que se entende por operação. Esse termo é definido como sendo acontecimentos, isto é, atualizações de 
possibilidades de sentido da comunicação que acontece no interior do sistema. Isso, porque Luhmann compreende os sistemas como fechados operacionalmente, ou seja, não há comunicação entre sistema e ambiente. O ambiente apenas funciona irritando(8) o sistema, fazendo com este interprete o elemento comunicativo externo à luz de sua própria linguagem.

O fechamento operacional traz para o sistema a necessidade de autoregulação. Destarte, ele lança mão de um código próprio. $\mathrm{O}$ código(9), é o elemento que, em última instância, ordena a totalidade do processo, em torno do qual os outros elementos gravitam e estabelecem configurações variáveis.

Esteves (1993) irá afirmar que para Luhmann o código é o elemento que permite as operações no interior do sistema, produz informações e identifica ruído. Ele é capaz de separar o que é sistema do ambiente e tem como característica ser formado por um binarismo que faz com que o sistema funcione assimetricamente e, com isso, oculte os paradoxos existentes em seu interior, bem como as tautologias. Daí decorre seu caráter eminentemente funcional. Deve ainda ser destacado, que é o próprio sistema que produz seu código. Com isso Luhmann, conforme Álvarez (2003:304), afirma que os sistemas são autopoiéticos:

"A este nivel de discusión el concepto de autopoiesis de Humberto Maturana significa un elemento nuevo. Los sistemas autopoiéticos son los que producen por sí mismos no sólo sus estructuras, sino también los elementos de que están compuestos, precisamente en la trama de estos elementos."

De tudo o que foi afirmado, Álvarez (2003:293) lança mão de um pergunta: como se configura o sistema e suas relações com o ambiente, se não são capazes de manter relações recíprocas? Vislumbra-se, então, a necessidade de aclaração do que seja o acoplamento estrutural, para a teoria dos sistemas e como ele funciona na relação entre sistema e ambiente.

Como afirma Luhmann, citado por Álvarez (2003:293):

"Volviendo al pensamiento de Humberto Maturana, hablaremos de "acoplamiento estructural". Este concepto presupone que todo sistema autopoiético opera como sistema determinado por la estructura, es decir, como un sistema que pueda determinar las propias operaciones sólo a través de las propias estructuras. El acoplamiento estructural, entonces, excluye el que los datos entorno puedan especificar, conforme a las propias estructuras, lo que sucede en al sistema. Maturana diría que el acoplamiento estructural se encuentra de modo ortogonal con respecto a la autodeterminación del 
sistema. No determina lo que sucede en el sistema, pero debe estar presupuesto, ya que de otra manera la autopoiesis se detendría y el sistema dejaría de existir. En este sentido, todos los sistemas están adaptados a su entorno (o no existirían), pero hacía el interior del radio de acción que así se les confiere, tienen todas las posibilidades de comportarse de un modo adaptado, y para ver muy claramente el resultado de estas posibilidades, basta considerar los problemas ecológicos de la sociedad moderna."

É o acoplamento estrutural, então, que permitirá uma convivência entre sistema e ambiente, sem que o sistema se veja agredido pelo ambiente, apenas irritado, e até mesmo ameaçado de existência. É o que poderia acontecer com a Religião e a Política, caso a primeira fosse capaz de corromper o código da política (poder e não-poder) a ponto de dissolver a segunda em seu interior.

Assim, o acoplamento estrutural permite o duplo efeito de inclusão e exclusão, além de concentrarem e selecionar as irritações do ambiente, o que gera o efeito paradoxal de torná-las imperceptíveis (ÁLVAREZ, 2003: 294).

As irritações surgem como uma confrontação da ordem interna do sistema com os eventos externos. Dessa forma, pode-se afirmar que se trata sempre de uma autoirritação, pois o sistema encontra em si mesmo as causas da irritação e aprende com isso, quer para imputar a irritação ao ambiente e, com isso, tratá-la como casual, quer para buscar sua origem e eliminá-la (ÁLVAREZ, 2003:294).

Após os presentes esclarecimentos, apresentando os pressupostos básicos que delineiam a Teoria dos Sistemas de Niklas Luhmann, pode-se avançar o presente trabalho, de modo a centrar nosso estudo no sistema do direito. Conforme declarará Luhmann, ele terá a função de estabilizar expectativas de comportamento na sociedade, utilizando-se para tanto do código direito / não-direito e estabelecendo um acoplamento estrutural com o sistema da política por meio da Constituição.

2 - A função dos Tribunais Constitucionais no Sistema do Direito

2.1 - O que é a Constituição para a Teoria dos Sistemas? Uma reflexão sobre o Sistema do Direito e o Sistema da Política

Após uma breve introdução ao pensamento luhmanniano, o presente estudo centrará sua atenção no direito, enquanto sistema social. Para tanto, torna-se imprescindível um debate acerca da compreensão luhmanniana do que seja uma Constituição. Primeiro, porque o tema em discussão remete à compreensão do papel dos Tribunais Constitucionais no Sistema do Direito, é necessário desfazer alguns 
equívocos, por exemplo, a afirmação de que tais tribunais se destinariam à "guarda" da Constituição. Em segundo lugar, devido ao papel vital desempenhado pela Constituição como elemento de acoplamento estrutural entre o Sistema do Direito e o Sistema da Política.

Desta feita, dois importantes escritos que serão tomados como guias na presente investigação são os textos de Luhmann, cuja tradução para o vernáculo poderia ser:

1. A Constituição como Aquisição Evolutiva(10), de 1996; e

2. O Direito da Sociedade(11), publicado em sua versão original na Alemanha em 1993.

Uma vez que se é capaz de compreender a sociedade como um problema altamente complexo, resultante de diversos processos de diferenciações, pode-se perceber que

"el problema de referencia de la función del derecho lo definimos en un plano más abstracto que como lo hace el derecho mismo. Los lógicos, quizás, describirán esto como la apertura de la tautología, es decir como la disolución del círculo autorreferencial en identidades que son diferenciables. La hipótesis señala: el derecho resuelve un problema temporal que se presenta en la comunicación social, cuando la comunicación en proceso no se basta a sí misma (ya sea como expresión, ya sea como "práctica") y tiene que orientarse y expresarse en expectativas de sentido que implican tiempo" (LUHMANN, 2002: 182)

É por isso que a função do direito está relacionada com expectativas, isto é, com a possibilidade de comunicação de expectativas de comportamento e, com isso, ao reconhecimento da comunicação. Isto porque ele tem uma função "de prepararse, al menos en el nivel de las expectativas, ante un futuro incierto - genuinamente incierto. Por eso con las normas varían la medida en que la sociedad produce un futuro acompañado de inseguridad" (LUHMANN, 2002:187). Ganha, então, relevância a questão da repetição, a fim de tentar estabilizar tal insegurança, pois uma vez que a comunicação necessita da figura do tempo para que, através da repetição, possibilite afirmações, reduz-se com isso a arbitrariedade na relação entre o signo e o significado.

Mas a relação entre tempo e estabilização de expectativas se dá por meio contrafático, mantendo uma permanente contradição com o âmbito social, uma vez que nesse as conexões temporais normativas produzem novas oportunidades de consenso e dissenso, isto é, são situações nas quais a própria decisão deve tomar partido contra ou a favor de uma determinada expectativa (LUHMANN, 2002:187). As conexões temporais, portanto, produzem tanto a conformidade 
quanto o desvio de condutas. Há, então, uma permanente tensão entre a dimensão temporal e a dimensão social, o que faz com que a norma fique sempre aberta para possibilidades de seu descumprimento.

É por tudo isso que Luhmann irá afirmar que uma das conseqüências mais importantes da forma normativa e da função do direito é permitir sua diferenciação com o Sistema da Política (LUHMANN, 2002:207).

“Para su aplicación el derecho depende de la política y sin la perspectiva de esta imposición no existe ninguna estabilidad normativa convincente que sea atribuible a todos. La política, a su vez, utiliza el derecho para diversificar el acceso al poder concentrado políticamente" (LUHMANN, 2002:208)

Mas isso não quer dizer que ambas se confundam, pois preexiste a diferenciação funcional entre direito e política. A política, distintamente do direito, faz uso do meio do poder, de modo que o poder político se articule como um poder indicativo superior que ameaça com seu caráter obrigatório.

“En cuanto las tendencias políticas de una decisión que vincula colectivamente se integran a un interruptor que y transforma las luchas de planeación en decisiones realizables, entonces se puede obligar a su cumplimiento. El "deber" de la norma, sin embargo, no presupone ninguna superioridad del poder; es más: ninguna superioridad por parte de quien articula las expectativas correspondientes". (LUHMANN, 2002:208)

É a partir de tais premissas que a Teoria dos Sistemas coloca o que se compreende por constituição, que não é vista como um resultado de um planejamento intencional, pois

"Ainda que se admita que as intenções dos atores exerçam qualquer papel na evolução sócio-cultural, se se trata da evolução em geral, os atores só exercem o papel do caso (um papel ocasional, vinculado ao caso). É possível que os atores se deixem guiar por critérios racionais, mas se se trata da evolução em geral, não é possível que daí se possa derivar qualquer conclusão sobre o resultado total". (LUHMANN, 1996:01)

Mas, então, porque a Teoria dos sistemas deveria voltar seus olhos para a Constituição, se como bem reconhece Giancarlo Corsi a "sociologia raramente ocupou-se da Constituição" (2001:169)? Contudo, o mesmo autor já adianta uma resposta ao lembrar da complexidade que envolve todo o tema: 
"Se perguntarmos aos juristas o que é a "Constituição", encontraremos respostas bastante heterogêneas, mas que compartilham a idéia de que a Constituição é importante, sobretudo, porque marca a imposição do Direito positivo sobre o Direito natural, porque vincula da forma completa o poder $r$, também porque é universal: nisso se encontra sua novidade e sua ruptura com as representações normativas do passado." (2001:171)

Partindo de uma análise das Revoluções Norte-americana e Francesa, respectivamente, a sociologia, pelo prisma de uma Teoria dos Sistemas, passa a compreender a constituição de maneira completamente diversa que faz o direito - no sentido que este a atribui de fundamento ou vínculo último do direito.(12) Como dirá Luhmann (1996: 02):

“A minha tese será a de que o conceito de Constituição, contrariamente ao que parece à primeira vista, é uma reação à diferenciação entre direito e política, ou dito com uma ênfase ainda maior, à total separação de ambos os sistemas de funções e à conseqüente necessidade de uma religação entre eles."

Ou seja, como dirá Corsi, trata-se de um:

"acoplamento estrutural de direito e política", entendendo-se esses como dois diferentes subsistemas da sociedade atual. Com essa formulação - muito abstrata, como sempre quando se trata da teoria dos sistemas - pretende-se descrever a situação na qual dois sistemas são completamente autônomos e, mediante uma estrutura comum (no caso, a Constituição), especificam, de modo extremamente circunscrito e seletivo, as possibilidades de "se irritarem" reciprocamente; no nosso caso, basta pensar na legislação como constante fator de irritação do Direito por parte da Política. Diversamente do que pode parecer à primeira vista, portanto, a invenção da Constituição é, sobretudo, uma reação à diferenciação (moderna) entre Direito e Política e uma tentativa de resolver (ou esconder!) os seus problemas: o problema da soberania popular e o problema da positivação (autodeterminação) do Direito." (2001:172173)

Sobre como se deu esse processo, esclarecerá Luhmann (1996:03):

“Em 1789, a França recepciona o conceito inglês de constitution conjuntamente com todas as suas imprecisões e, sobre essa matriz, limita-se simplesmente a discutir as dimensões da redistribuição sempre necessária dos pesos. Na América, ao contrário, em contraposição à situação jurídica inglesa, acentuava-se a unidade do texto constitucional redigido de forma escrita. O que requeria uma 
determinação conceitual que introduzisse uma distinção entre a Constitution e os demais Direitos, em clara discrepância com o uso lingüístico inglês. Tal como freqüentemente se compreende, também neste caso, é uma distinção que possibilita que se deixe na indeterminação aquilo que se distingue. A Constituição não é senão este texto e nenhum outro. É de se acrescentar ainda que a ocasião da revolução política conduz à pretensão de se limitar juridicamente às possibilidades de ação de qualquer órgão do estado, ou seja, à ruptura da onipotência do próprio Parlamento. O que, por sua vez, produz efeitos posteriores e constringe a que se conclua que a Constituição deva ser supraordenada em relação a todos os demais direitos. Essa idéia só parece haver surgido após a Declaração da Independência de 1776. Portanto, ela deve ser compreendida como uma inovação de origem política no interior do próprio sistema do direito: no passado, havia, é certo, a idéia de leis particularmente importante e fundamentais, mas não a idéia de que houvesse uma lei que servisse de medida da conformidade ou não-conformidade ao direito de todas as outras leis e atos jurídicos. Essa posição particular, no entanto, encontra a sua expressão no fato de que a Constituição, por sua vez, relaciona-se com os demais direitos e contém uma regra de colisão para a hipótese de uma contradição entre ela e o demais direito. A Constituição atribui a si própria a primazia e rompe com a regra segundo a qual lex posterior derogat legi priori. Essa estrutura "autológica," que se autoinclui no próprio âmbito de regulamentação, evidencia como a Constituição encontrase destinada a se tornar direito velho.

Todo o direito é posto, agora, em uma situação de problematicidade, de contingência, pois, mesmo o legislador sendo capaz de criá-lo, não quer dizer que ele possa ser lícito. A Constituição passa a ser o vetor de ordenação do código direito/não-direito e, com isso, atuando para a fundação da validade do direito. É, então, que o direito, como sistema auto-referencial, adquire as características dadas pela Teoria dos Sistemas:

"Todos os sistemas autoreferenciais são caracterizados (1) por uma circularidade fundamental e (2) pela impossibilidade de se reintroduzir operativamente a unidade do sistema em seu interior. A cada tentativa de se descrevê-lo a circularidade fundamental surge como uma tautologia e, negativamente, como paradoxo. Quem distingue sistema e ambiente - da perspectiva do sistema ou do ambiente - deve antes de tudo completar tal distinção e utilizá-la operativamente e, então, não pode mais recomparecer na distinção como quem distingue a distinção. Eles atuam a um só tempo como Ulisses e como a invisível Atena. Em ambos os lados da distinção, as condições reais para se poder diferenciar (no âmbito de nosso tema: a factualidade da comunicação social) não são reproduzíveis. A impossibilidade lógica de se fazer ressurgir novamente de alguma 
parte, não importa se do sistema ou do ambiente, a unidade do sistema, revela a inadequação de todas as autodescrições. Se, como o resultado de uma longa evolução sócio-cultural, o direito se diferencia na forma de um sistema autoreferencial fechado e se isso pode ser adequadamente descrito tanto do ponto de vista interno quando do externo, tornar-se-á agora necessário que se faça as contas com ambos os problemas anteriormente citados, ou seja, com a tautologia e o paradoxo" (LUHMANN, 1996:04, grifos nossos)

O direito pode produzir seu próprio elemento de distinção dos demais sistemas através da orientação de seu código binário específico direito/não-direito. Assim, o recurso à positivação permite ao direito sua unidade e sua autofundação.

“Com efeito, positividade não significa senão que o direito só possa ser criado pelo próprio direito e não ab extra pela natureza ou pela vontade política. Em outras palavras, o termo positividade não faz mais do que expressar em uma linguagem datada a autodeterminação operativa do direito e não, como se afirma freqüentemente, a fundação da validade do direito através de um ato de arbítrio político. Dito de outro modo, se se objetiva conhecer o direito vigente é o direito e não a política que é de se observar". (LUHMANN, 1996:04)

Deste modo, a Constituição permite o fechamento do Sistema do Direito, mediante o seu reingresso no sistema.

“Em outros termos, a Constituição deve deslocar aqueles sustentáculos externos que haviam sido postulados pelo jusnaturalismo. Ela substitui quer o direito natural em sua versão cosmológica mais tradicional, quer o direito racional com o seu concentrado de teoria transcendental que se auto-refere a uma razão que julga a si própria. No lugar dessa última, subentra um texto parcialmente autológico. Isso é, a Constituição fecha o sistema jurídico ao discipliná-lo como um âmbito no qual ela, por sua vez, reaparece". (LUHMANN, 1996:05)

Já com relação ao Sistema da Política, a necessidade de uma constituição é justificada à luz do problema da soberania caracterizada como a unidade do sistema a partir de um problema de decisão, ou seja, quais decisões podem ser vinculantes e quais não. Conforme Luhmann (1996:08):

“No sistema político, mutatis mutandis, são reconhecíveis os problemas de autoreferenciabilidade que também irritam o sistema jurídico. Na fórmula da soberania se expressa uma tautologia: eu decido como decido. Se se acrescenta uma negação emerge um paradoxo: eu decido sem vínculos com efeitos vinculantes para todos 
inclusive também para mim mesmo a partir do momento em que faço parte do sistema: eu me vinculo e me desvinculo. Além do mais é evidente que esse "privilégio" só pode ser praticado em um lugar, ou seja, apenas em operações específicas. O sistema soberano requer o soberano - ainda que esse seja o "povo." No sistema, o decidir soberanamente é não apenas respeitado e dotado de poder de ação, mas também observado. Sob esse aspecto, a soberania define não mais o direito a um arbítrio incondicionado (o que no plano empírico seria dificilmente imaginável), mas apenas um indirizzo, uma diretriz, daí a regra: observa o observador que exerce a soberania no sistema."

É justamente a partir do acoplamento estrutural entre o Sistema do Direito e o Sistema da Política que se pode encontrar uma estabilidade de ambos os sistemas.

"A partir do momento que o sistema político resolve com a Constituição os problemas de sua própria referenciabilidade, esse emprega, portanto, o direito. Esse emprego do direito só pode funcionar, no entanto, porque os sistemas não são congruentes, porque não se sobrepõem nem mesmo em uma medida mínima, mas, ao contrário, o sistema político pode se servir do sistema jurídico mediante heteroreferenciabilidade e, assim, mediante o recurso a um outro sistema funcional. O conceito de Estado, do mesmo modo, assinala a um só tempo uma organização e uma pessoa jurídica segundo o sistema a partir do qual se o considera. Analogamente, a imensa amplitude do âmbito de aplicação que o poder político alcança com a dúplice codificação jurídica de todas as decisões políticas é condicionada pela nítida diferenciação dos sistemas." (LUHMANN, 1996: 10).

Tomando por base toda essa discussão até aqui desenvolvida, Araújo Pinto (2004:149) ressaltará a importância do controle de constitucionalidade - característico das constituições modernas ao lado da supremacia da própria Constituição - como mecanismo de manutenção desse acoplamento estrutural e conseqüente fator de diferenciação entre o Sistema do Direito e o Sistema da Política.

No tópico seguinte será então examinado o papel que a Teoria dos Sistemas coloca para os tribunais, principalmente para os Tribunais Constitucionais. Já que como lembra Juliana Neuenschwander Magalhães (1999:443), são eles os responsáveis pela distribuição dos códigos direito/não-direito, tomando para tanto a validade do direito estabelecida, principalmente pela Constituição.

2.2 - Mas, então, o Tribunal Constitucional guarda o quê? 
Após a descrição de como a Teoria dos Sistemas compreende a constituição, torna-se mais simples perceber o papel que os Tribunais Constitucionais deverão assumir. Já de início, salta aos olhos que sua visão em nada se compara com as concepções clássicas, quer como a entende a Teoria Positivista do Direito, como a versão normativista de Hans Kelsen (1999:248), na qual a Constituição era posta no ápice do escalão do direito positivo, quer como a posição defendida por Carl Schmitt (1996), no sentido de cisão política fundamental de um povo.

Como Luhmann irá criticar, a concepção kelseniana de constituição ainda carece de apoio em uma fundamentação última, que somente encontra respaldo através da pressuposição de uma norma fundamental hipotética (KELSEN, 1999:09).

"A validade da Constituição não pode e não deve mais ser fundada ab extra. Também a validade hipotética de uma norma fundamental (Kelsen), modelada por analogia com os procedimentos da ciência tampouco satisfaz. Na melhor das hipóteses é uma construção supérflua. Podemos agora compreender como toda reproposição do problema da origem ou do fundamento de validade, da arché ou do principium tinha pouco sentido. $\mathrm{O}$ abandono desse enfoque, de fato, não significa a abertura para a arbitrariedade ou, como se costuma temer na Alemanha, o retorno dos nacionais-socialistas. Abre-se, ao contrário, a possibilidade de se analisar mais de perto quais requisitos um texto parcialmente autológico deve cumprir em um sistema autoreferencial operativamente fechado." (LUHMANN, 1996:05)

Essa criação - que é sem dúvida engenhosa - é, porém, inútil aos olhos da Teoria dos Sistemas, já ignora por completo a dimensão semântica que a Constituição adquire para o Sistema da Política.

De igual modo, uma teoria como a schmittiana que acaba por diluir o Sistema do Direito no Sistema da Política, através da compreensão de constituição como decisão política fundamental (SCHMITT, 1996:47), também se mostra ineficiente.

Mas, curiosamente, é principalmente o debate entre ambos que propiciou a afirmação histórica do Judiciário como o "guardião" da Constituição, para usar a expressão que ficou consagrada (KELSEN, 2003; SCHMITT, 1998).

Schmitt, de um lado, defendia que tal papel somente poderia ser desempenhado pelo Monarca ou pelo Presidente do Reich, no caso alemão. Isto, porque, em sua teoria, é somente o Chefe do Executivo que poderia ocupar uma posição neutra, mediadora e reguladora dentro do Estado, uma vez que era o escolhido de uma nação - como lembra Chantal Mouffe (1994:90), compreendida como uma unidade homogênea - que em uma única voz aclama o Presidente que os irá 
representar.(13) Destarte, ponto inicial do pensamento de Schmitt estava na questão da decisão (14) do Estado. Ele rejeita a limitação imposta à decisão judicial, pois afirma, contrariamente a Kelsen, que "normas não caem do céu", por isso não podem ser baseadas em um direito natural, racional ou mesmo em norma hipotéticas, mas sim ser fruto da vontade do soberano, o Estado. Como lembra Arruda (2003: 78): "o Estado não é somente aquele que tem o monopólio do poder, mas também que detém o monopólio das decisões morais".

A Constituição, por sua vez, não foge a mesma regra. Como lembra Vanessa Oliveira Batista (1999:173-174), o próprio conceito de Constituição, para Schmitt, já deriva da idéia de decisão, pois é nada mais que documento produto de decisão conjunta de um povo sobre sua existência política. Assim, o Estado não tem uma Constituição, mas sim deve-se dizer que ele é a própria Constituição, ou seja, é a unidade e ordem (BATISTA, 1999:180). Desta forma, o Estado schmittiano segue de perto as concepções da Igreja Católica, principalmente, no tocante à questão da representação.(15)

Por sua vez, Kelsen é enfático em afirmar que um tribunal constitucional é plenamente o mais indicado a assumir o papel de guardião. Assim, nega que tal papel possa ser desempenhado pelo Judiciário como um todo, como acontece no modelo norte-americano (16), mas sim por um órgão que centralizaria toda a controvérsia constitucional.

"A vantagem dessa solução [dirá Kelsen] consiste no fato de que os diferentes órgãos aplicadores da lei podem ter opiniões deferentes com respeito à constitucionalidade de uma lei e que, portanto, um órgão pode aplicar a lei por considerá-la constitucional, enquanto outro the negará aplicação com base na sua alegada inconstitucionalidade. A ausência de uma decisão uniforme sobre a questão da constitucionalidade de uma lei, ou seja, sobre a Constituição estar sendo violada ou não, é uma grande ameaça à autoridade da própria Constituição." (KELSEN, 2003:303)

Devido a tal posição, concebe-se que o procedimento de julgamento seria, então, tido como objetivo, ou seja, independente do pedido da parte requerente - que no caso kelseniano, se limitaria à pessoa do promotor geral. Mas tal afirmação, só em si mesmo, não acrescente novidades no pensamento de Kelsen, já que o magistrado sempre tem um espaço de discricionariedade, no qual poderá aplicar o direito utilizando-se, para tanto, de uma moldura das interpretações possíveis, ou segundo a edição francesa da Teoria Pura do Direito, este poderia, ainda, se valer de interpretações que não estivessem dentro de tal moldura interpretativa (KELSEN: 1999:393). Como lembra Cattoni de Oliveira (2001:51), tal posicionamento acaba por colocar em "panne" a própria teoria, abrindo margem para um 
decisionismo jurídico, que subverte a distinção, até então estabelecida, entre ser e dever ser.

Sob o ponto de vista da Teoria dos Sistemas, esta poderia ler o posicionamento kelseniano como a autorização para a corrupção do código do direito, por outros códigos, como o código da política, por exemplo. Desta forma, indaga-se: como poderia o Tribunal Constitucional ser o "guardião" de uma Constituição, em Kelsen, se nem ao menos devesse se submeter as suas normas?(17)

Ingeborg Maus (2000:191) irá denunciar que o reconhecimento por parte do Tribunal Constitucional de uma competência ampla acaba por permitir que seus membros possam passar a analisar, inclusive, 0 "direito supra positivo", permitindo, assim, controlar a própria Constituição e com isso determinar a fixação da interpretação "devida". Com isso o Judiciário subverte a ótica da separação dos poderes, invadindo a competência típica do Legislativo.(18)

E mais, passa a ser o Tribunal Constitucional o elemento produtor do código jurídico, desestabilizando o acoplamento estrutural que antes havia entre Direito e Política. Vê-se, então, a total impossibilidade de sustentar tal tese à luz de uma teoria luhmanniana - que além de tudo atribui à Constituição significado diverso dos atribuídos pelas teorias correntes, como já visto.

É, portanto, necessário compreender a distinção entre legislação e jurisdição a partir da Teoria dos Sistemas.

“Con ayuda de la relación asimétrica entre legislación y jurisprudencia y con la ayuda de medios conceptuales derivados (por ejemplo la doctrina de las fuentes del derecho) se intenta evitar la circularidad que resultaría de admitir que el tribunal "crea" el mismo derecho que "aplica". (...) El círculo no tendría lugar si los tribunales en el momento en que no dieran con el derecho, en lugar de decidir se contentaran con aseverar que no está claro ("non liquen"). Esto, sin embargo no se permite desde el punto de vista del derecho. El hecho de que el sistema internamente se vea en la necesidad de decidir no es más que la consecuencia que corresponde al desacoplamiento del sistema con respecto a toda participación directa del entorno (clausura operativa del sistema). El estado del sistema no es un resultado del estado del mundo. La distinción sistema/entorno se experimenta en el sistema como un problema abierto y, al final de una larga experiencia con esta clausura y después del desarrollo de ordenamientos jurídicos que hacen esto posible, el sistema mismo se coacciona a decidir." (LUHMANN, 2002:368-369) 
Contudo, uma pergunta ainda fica: o Tribunal Constitucional guarda o quê? Dito de outro modo: Sobre o que decidem esses Tribunais, já que a decisão é um comportamento de qualquer sujeito cognoscente?

"La decisión tiene siempre que ver con una alternativa: uno o más senderos elegibles - los que, a su vez, contienen situaciones, acontecimientos y también subsecuentes decisiones que resultan de esa primera decisión. Por consiguiente las decisiones subsecuentes no se podrían realizar sin una primera. Estas decisiones subsiguientes son previsibles dentro de márgenes muy restringidos, y si se trata de una pluralidad de decisiones son, en definitiva, imprevisibles. Sin embargo, la decisión misma no es un componente de la alternativa: no es uno de los senderos. Por eso hay que suponer que la decisión es el tercio excluso de la alternativa de a alternativa. Es la diferencia que constituye la alternativa, o con más precisión: es la unidad de esta diferencia." (LUHMANN, 2002:369-370)

Com isso, a Teoria dos Sistemas nos remete a um paradoxo. Este somente pode ganhar contornos cognoscíveis a partir de um ponto cego, que atua como elemento que rompe com essa assimetria, que será a dimensão temporal que o direito apresenta.

"Como esto [a dimensão temporal do direito] es posible, entonces se puede utilizar el presente como momento de la decisión: solidificar lo ya-no-cambiable (con relación al pasado) y lo todavía-cambiante (con relación al futuro) para introducir en el mundo (que es simultáneo) la forma de una alternativa. (...) Con este comportamiento selectivo se puede construir una alternativa que, por su parte, permite aprehender la situación como situación de decisión. Una decisión de lleva a cabo tan sólo si se temporaliza de esa manera. Por lo demás queda al libre albedrío experimentar el presente del mundo tal como se muestra" (LUHMANN, 2002:370-371)

Assim, a decisão passa a operar, no presente, dentro de sua própria construção, não estando presa ao passado, mas lançando pretensões de determinar o futuro, considerando, para tanto, as conseqüências advindas dessas decisões. Assim, tal colocação acaba por nos conduzir "à questão de sabermos se os efeitos do direito podem ser considerados como critérios para a determinação do próprio direito: em outras palavras, se o direito pode ser orientado por suas conseqüências" (MAGALHÃES, 1999: 444). É por isso que

"todo sistema de função necessita de um nível decisório dotado de uma elevada capacidade de agregação, que possa ser referência para um grande número de decisões, não obstante os detalhes de cada caso. Em se tratando do sistema do direito, este nível mais abstrato 
vai ser constituído, em parte, pela dogmática jurídica (através de seus conceitos e de suas teorias) e, em parte, no interior da casuística relativa aos princípios derivados da jurisprudência dos tribunais superiores." (MAGALHÃES, 1999: 445)

Mas os tribunais somente podem decidir com base no código jurídico - direito/não-direito - abandonando qualquer enfoque moralista, político ou utilitarista, isto é orientado ao benefício econômico da sociedade (LUHMANN, 2002:380).

É, por isso, que decisões sobre Constituição ganham relevo para o sistema do Direito, pois fornecem duas importantes conseqüências. Uma é reafirmar que Constituição traz em si uma garantia procedimental (CATTONI DE OLIVEIRA, 2000:130), sobre o modo como se deverão estruturar as decisões, sem, contudo, afirmar quem ela irá favorecer, o autor ou o réu. Isto é representado, por exemplo, pelos princípios do acesso ao Judiciário e pela exigência de imparcialidade das decisões e pela noção de devido processo legal.

Outra conseqüência é que as decisões, por serem frutos das próprias questões e controvérsias decidas pelos Tribunais, transformam-se em referência para a interpretação do próprio código em decisões subseqüentes, permitindo, de tal sorte, certa margem de previsibilidade, que contribuí na redução da complexidade do sistema e reafirma a função do direito, como elemento de estabilização de expectativa de comportamento.

Assim, isso explica porque o Judiciário ocupa o centro do Sistema do Direito, como afirma Luhmann (2002:383) e permite que se vislumbre que o Tribunal Constitucional, em todo caso, se apresenta como o núcleo desse sistema. Sua atividade, portanto, não é de proteção da Constituição, mas o de fornecimento de decisões a partir do código direito/não-direito, que além de interpretar o próprio código, fornecem referenciais para as decisões posteriores e atuam como instância primária da diferenciação do direito e do seu ambiente.

\section{CONCLUSÃO}

O presente trabalho buscou apresentar uma resposta à pergunta a que se propôs: como se pode compreender o papel desempenhado pelos assim chamados Tribunais Constitucionais dentro do Sistema do Direito?

Para tanto se iniciou por apresentar os conceitos principais que delineiam toda a teoria luhmanniana, bem como em explicar por que ela pode representar uma resposta adequada ao atual cenário em 
que se encontra a sociedade. Dito de outro modo: a Teoria dos Sistemas objetiva explicar e descrever como a sociedade passou a se estruturar após a sua entrada na modernidade, principalmente, com o desenvolvimento da concepção de indivíduo, que muito mais complexa que as antigas dicotomias, por exemplo, a fixada entre gregos e bárbaros, que por si só davam conta de sintetizar todos os reflexos produzidos.

Hoje esse aumento de complexidade pode ser observado como um processo de diferenciação funcional da sociedade, que passou a reagir de modo diverso aos diferentes estímulos existentes. Direito, Política, Religião, etc. passam a constituir cada qual um sistema presente no interior da sociedade que busca dar respostas próprias a problemas que também lhe são bem próprios.

Inegável, portanto, o aumento de complexidade que se instalou no seio dessa sociedade. $E$ assim, se pode observar a importância e atualidade do pensamento de Niklas Luhmann, pois para esse autor, como visto, a complexidade não representa um obstáculo, mas constitui a própria condição de existência do sistema social. Como lembra Álvarez (2003:278) e Dario Rodriguez (2002:28-29) os sistemas surgem, justamente, como forma de redução dessa complexidade. Limitando o olhar para o interior do sistema que passa a ficar circunscrito em si, lendo tudo mais como seu ambiente e operando através de um código que lhe seja próprio.

Sistema é, então, um "conjunto de elementos inter-relacionados, cuja unidade é dada por suas interações e cujas propriedades são distintas da soma desses elementos" (CHAl, 2004:50). É a identificação de uma igualdade em uma diferença que projeta a distinção entre sistema e ambiente (ÁLVAREZ, 2003: 281), deste modo, o sistema se constitui e se conserva mediante a criação e recriação dessa diferença. Tal processo permite ao sistema desenvolver a autoreferência, isto é, "capacidade de estabelecer aquelas relações entre si ao mesmo tempo em que diferenciam essas relações das relações mantidas com seu ambiente" (CHAl, 2004:50), e que permitem o fechamento operacional do mesmo sistema.

O próximo conceito a ser compreendido é, então, o de operação. Esse termo foi definido como sendo acontecimentos, isto é, atualizações de possibilidades de sentido da comunicação que acontece no interior do sistema. Isso, porque Luhmann compreende os sistemas como fechados operacionalmente, ou seja, não há comunicação entre sistema e ambiente. O ambiente apenas funciona irritando o sistema, de modo que este interprete o elemento comunicativo externo à luz de sua própria linguagem. 
O fechamento operacional traz, dessa forma, para o sistema a necessidade de autoregulação. Destarte, ele lança mão de um código próprio. O código é o elemento que ordena a totalidade do processo, em torno do qual os outros elementos gravitam e estabelecem configurações variáveis. Conforme Esteves (1993), o código é o elemento que permite as operações no interior do sistema, que produz informações e que identifica um ruído. Ele separa o que é sistema do ambiente e se forma através de um binarismo que faz com que o sistema funcione assimetricamente e, com isso, oculte os paradoxos existentes em seu interior, bem como as tautologias. Daí decorre seu caráter eminentemente funcional.

Também como destacado, que é o próprio sistema que produz seu código, o que remete a idéia de autopoiesis importada da teoria biológica de Maturana e Varela. Os sistemas são autopoiéticos, porque são capazes de produzir por si mesmos não somente suas estruturas, como também os elementos de que são compostos. ( Álvarez 2003: 304).

Em seguida, buscou-se responder a pergunta formulada por Álvarez (2003:293): como se configura o sistema e suas relações com o ambiente, se não são capazes de manter relações recíprocas? Para tanto, fez-se a necessário aclarar o que seja o conceito de acoplamento estrutural para a teoria dos sistemas e como ele funciona na relação entre sistema e ambiente.

Como afirmado por Luhmann (apud Álvarez, 2003:293), este conceito pressupõe que todo sistema autopoiético opera como um sistema que pode determinar suas próprias operações somente através de suas próprias estruturas. É através do acoplamento estrutural que se permitirá uma convivência entre sistema e ambiente, sem que o sistema se veja agredido pelo ambiente, apenas irritado, e até mesmo ameaçado de existência. O acoplamento estrutural permite ainda o duplo efeito de inclusão e exclusão, além de concentrarem e selecionarem as irritações do ambiente, o que gera o efeito paradoxal de torná-las imperceptíveis (ÁLVAREZ, 2003: 294).

As irritações, por sua vez, surgem como uma confrontação na ordem interna do sistema com os eventos externos. Dessa forma, pode-se afirmar que se trata sempre de uma autoirritação, pois o sistema encontra em si mesmo as causas da irritação e aprende com isso, quer para imputar a irritação ao ambiente e, com isso, tratá-la como casual, quer para buscar sua origem e eliminá-la (ÁLVAREZ, 2003: 294).

Após tais considerações, o trabalho voltou seu olhar para o Sistema do Direito, para tentar explicar qual a semântica que os Tribunais 
Constitucionais adquirem em seu interior. Mas, para tanto, foi necessário aclarar o que a Teoria dos Sistemas entende por Constituição.

Pode-se afirmar que a função do direito está relacionada com expectativas, isto é, com a possibilidade de comunicação de expectativas de comportamento e, com isso, ao reconhecimento da comunicação. Ganha, então, relevância a questão da repetição, a fim de tentar estabilizar tal insegurança, pois uma vez que a comunicação necessita da figura do tempo para que, através da repetição, possibilite afirmações, reduz-se com isso a arbitrariedade na relação entre signo o significado (LUHMANN, 2002:187).

Mas, como visto, a relação tempo/estabilização de expectativas se dá por meio contrafático, o que mantém uma permanente contradição com o âmbito social, uma vez que nesse as conexões temporais normativas produzem novas oportunidades de consenso e dissenso, isto é, são situações nas quais a própria decisão deve tomar partido contra ou a favor de uma determinada expectativa (LUHMANN, 2002: 187).

As conexões temporais, portanto, produzem tanto a conformidade quanto o desvio de condutas. Verifica-se, então, uma permanente tensão entre a dimensão temporal e a dimensão social, o que faz com que a norma fique sempre aberta para possibilidades de seu descumprimento. É por tudo que Luhmann irá afirmar que uma das conseqüências mais importantes da forma normativa e da função do direito é permitir sua diferenciação com o Sistema da Política (LUHMANN, 2002:207).

Mas isso não quer dizer que ambas se confundam, pois preexiste a diferenciação funcional entre direito e política. A política, distintamente do direito, faz uso do meio do poder, de modo que o poder político se articule como um poder indicativo superior que ameaça com seu caráter obrigatório.

Partindo de uma análise das Revoluções Norte-americana e Francesa, respectivamente, a sociologia, pelo prisma de uma Teoria dos Sistemas, passa a compreender a Constituição de maneira completamente diversa que faz o direito - no sentido que este a atribui de fundamento ou vínculo último do direito. Como dirá Luhmann (1996:02), a constituição é uma reação à diferenciação entre direito e política, ou dito com uma ênfase ainda maior, à total separação de ambos os sistemas de funções e à conseqüente necessidade de uma religação entre eles. Ou seja, como dirá Corsi, trata-se de um: 
"acoplamento estrutural de direito e política", entendendo-se esses como dois diferentes subsistemas da sociedade atual. Com essa formulação - muito abstrata, como sempre quando se trata da teoria dos sistemas - pretende-se descrever a situação na qual dois sistemas são completamente autônomos e, mediante uma estrutura comum (no caso, a Constituição), especificam, de modo extremamente circunscrito e seletivo, as possibilidades de "se irritarem" reciprocamente; no nosso caso, basta pensar na legislação como constante fator de irritação do Direito por parte da Política. Diversamente do que pode parecer à primeira vista, portanto, a invenção da Constituição é, sobretudo, uma reação à diferenciação (moderna) entre Direito e Política e uma tentativa de resolver (ou esconder!) os seus problemas: o problema da soberania popular e o problema da positivação (autodeterminação) do Direito." (2001:172173)

Todo o direito é posto, agora, em uma situação de problematicidade, de contingência, pois, mesmo o legislador sendo capaz de criá-lo, não quer dizer que ele possa ser lícito. A Constituição passa a ser o vetor de ordenação do código direito/não-direito e, com isso atuando para a fundação da validade do direito. O direito pode produzir seu próprio elemento de distinção dos demais sistemas através da orientação de seu código binário específico - direito/não-direito. Assim, o recurso à positivação permite ao direito sua unidade e sua autofundação. Deste modo, a Constituição permite o fechamento do Sistema do Direito, mediante o seu reingresso no sistema.

Já com relação ao Sistema da Política, a necessidade de uma constituição é justificada à luz do problema da soberania caracterizada como a unidade do sistema a partir de um problema de decisão, ou seja, quais decisões podem ser vinculantes e quais não. Conforme Luhmann (1996:08):

"No sistema político, mutatis mutandis, são reconhecíveis os problemas de autoreferenciabilidade que também irritam o sistema jurídico. Na fórmula da soberania se expressa uma tautologia: eu decido como decido. Se se acrescenta uma negação emerge um paradoxo: eu decido sem vínculos com efeitos vinculantes para todos inclusive também para mim mesmo a partir do momento em que faço parte do sistema: eu me vinculo e me desvinculo. Além do mais é evidente que esse "privilégio" só pode ser praticado em um lugar, ou seja, apenas em operações específicas. O sistema soberano requer o soberano - ainda que esse seja o "povo." No sistema, o decidir soberanamente é não apenas respeitado e dotado de poder de ação, mas também observado. Sob esse aspecto, a soberania define não mais o direito a um arbítrio incondicionado (o que no plano empírico seria dificilmente imaginável), mas apenas um indirizzo, uma diretriz, 
daí a regra: observa o observador que exerce a soberania no sistema".

É justamente a partir do acoplamento estrutural entre o Sistema do Direito e o Sistema da Política que se pode encontrar uma estabilidade de ambos os sistemas.

"A partir do momento que o sistema político resolve com a Constituição os problemas de sua própria referenciabilidade, esse emprega, portanto, o direito. Esse emprego do direito só pode funcionar, no entanto, porque os sistemas não são congruentes, porque não se sobrepõem nem mesmo em uma medida mínima, mas, ao contrário, o sistema político pode se servir do sistema jurídico mediante heteroreferenciabilidade e, assim, mediante o recurso a um outro sistema funcional. O conceito de Estado, do mesmo modo, assinala a um só tempo uma organização e uma pessoa jurídica segundo o sistema a partir do qual se o considera. Analogamente, a imensa amplitude do âmbito de aplicação que o poder político alcança com a dúplice codificação jurídica de todas as decisões políticas é condicionada pela nítida diferenciação dos sistemas." (LUHMANN, 1996: 10)

A partir dessa discussão, fica mais fácil compreender a importância do controle de constitucionalidade para o Sistema do Direito, que funciona como mecanismo de manutenção desse acoplamento estrutural e conseqüente fator de diferenciação entre o Sistema do Direito e o Sistema da Política.

Sob o prisma da Teoria dos Sistemas, tanto as concepções clássicas de Constituição defendidas por Hans Kelsen (1999) e Carl Schmitt (1996) se mostram insuficientes. De igual maneira a forma como ambos entendem que devesse se dar a proteção da Constituição, pela ação de um "guardião", que poderia ser um Tribunal ou o Chefe do Executivo, respectivamente.

Contudo, permanece a dúvida que permite atingir o objetivo especifico da presente monografia: sobre o que decidem esses Tribunais, para a Teoria dos sistemas?

Segundo Luhmann,

"La decisión tiene siempre que ver con una alternativa: uno o más senderos elegibles - los que, a su vez, contienen situaciones, acontecimientos y también subsecuentes decisiones que resultan de esa primera decisión. Por consiguiente las decisiones subsecuentes no se podrían realizar sin una primera. Estas decisiones subsiguientes son previsibles dentro de márgenes muy restringidos, y si se trata de una pluralidad de decisiones son, en definitiva, imprevisibles. Sin embargo, la decisión misma no es un componente de la alternativa: no es uno de los senderos. Por eso hay que suponer que la decisión 
es el tercio excluso de la alternativa de a alternativa. Es la diferencia que constituye la alternativa, o con más precisión: es la unidad de esta diferencia." (LUHMANN, 2002:369-370)

Com isso, a Teoria dos Sistemas nos remete a um paradoxo, que somente ganha contornos cognoscíveis a partir de um ponto cego, que atua como elemento que rompe com essa assimetria. Tal ponto cego será a dimensão temporal que o direito apresenta.

"Como esto es posible, entonces se puede utilizar el presente como momento de la decisión: solidificar lo ya-no-cambiable (con relación al pasado) y lo todavía-cambiante (con relación al futuro) para introducir en el mundo (que es simultáneo) la forma de una alternativa. (...) Con este comportamiento selectivo se puede construir una alternativa que, por su parte, permite aprehender la situación como situación de decisión. Una decisión de lleva a cabo tan sólo si se temporaliza de esa manera. Por lo demás queda al libre albedrío experimentar el presente del mundo tal como se muestra." (LUHMANN, 2002:370-371)

Sob essa luz, a decisão passa a operar, no presente, dentro de sua própria construção, não estando presa ao passado, mas lançando pretensões de determinar o futuro, considerando, para tanto, as conseqüências advindas dessas decisões.

Assim, tal colocação acaba por nos conduzir "à questão de sabermos se os efeitos do direito podem ser considerados como critérios para a determinação do próprio direito: em outras palavras, se o direito pode ser orientado por suas conseqüências". (MAGALHÃES, 1999: 444) É por isso que

"todo sistema de função necessita de um nível decisório dotado de uma elevada capacidade de agregação, que possa ser referência para um grande número de decisões, não obstante os detalhes de cada caso. Em se tratando do sistema do direito, este nível mais abstrato vai ser constituído, em parte, pela dogmática jurídica (através de seus conceitos e de suas teorias) e, em parte, no interior da casuística relativa aos princípios derivados da jurisprudência dos tribunais superiores." (MAGALHÃES, 1999:445)

Mas os tribunais somente podem decidir com base no código jurídico - direito/não-direito - abandonando qualquer enfoque moralista, político ou utilitarista, isto é orientado ao benefício econômico da sociedade (LUHMANN, 2002:380). É, por isso, que decisões sobre a Constituição ganham relevo para o Sistema do Direito, pois fornecem duas importantes conseqüências. Uma é reafirmar que Constituição traz em si uma garantia procedimental (CATTONI DE OLIVEIRA, 2000: 130), sobre o modo como se deverão estruturar as decisões, sem, contudo, afirmar quem ela irá favorecer, o autor ou o réu. 
Outra conseqüência é o fato de que as decisões, por serem frutos das próprias questões e controvérsias decidas pelos Tribunais, transformam-se em referência para a interpretação do próprio código em decisões subseqüentes, permitindo, de tal sorte, uma certa margem de previsibilidade, que contribui na redução da complexidade do sistema e reafirma a função do direito, como elemento de estabilização de expectativa de comportamento.

Assim, torna-se fácil compreender o porquê do Judiciário ocupar o centro do Sistema do Direito, como afirma Luhmann (2002:383) e permite que se vislumbre que o Tribunal Constitucional, em todo caso, se apresenta como o núcleo desse sistema. Assim, sua atividade não é de proteção da Constituição, mas o de fornecimento de decisões a partir do código direito/não-direito, que além de interpretar o próprio código, fornecem referenciais para as decisões posteriores e atuam como instância primária da diferenciação do direito e do seu ambiente.

\section{REFERÊNCIAS BIBLIOGRÁFICAS}

ALEXY, Robert. Teoría de los Derechos Fundamentales. Trad. Ernesto Garzón Valdés. Madrid: Centro de Estudios Constitucionales. 1993.

ÁLVAREZ, Emilio Geraldo Arringa. La Teoria de Niklas Luhmann. In: Convergência. México. n. 32. mai.-ago./2003. pp. 277-312.

ARAÚJO PINTO, Cristiano Otávio Paixão. A Reação Norte-americana aos Atentados de 11 de Setembro de 2001 e seu Impacto no Constitucionalismo Contemporâneo: um estudo a partir da teoria da diferenciação do direito. Tese de Doutorado apresentada à Faculdade de Direito da Universidade Federal de Minas Gerias. Belo Horizonte, 2004.

ARRUDA, José Maria. Carl Schmitt: Política, Estado e Direito. In: OLIVEIRA, Manfredo. AGUIAR, Odílio Alves. SAHD, Luiz Felipe Netto de Andrade e Silva (org.) Filosofia Política Contemporânea. Petrópolis: Vozes, 2003.

BATISTA, Vanessa Oliveira. Elementos de Teoria da Constituição: de Carl Schmitt aos dias de hoje. In: Revista de Direito Comparado. Belo Horizonte. Curso de Pós-Graduação em Direito da UFMG e Mandamentos. v. 3. mai./1999. pp. 165-201.

BAUMAN, Zygmunt. Modernidade Líquida. Trad. Plínio Dentzien. Rio de Janeiro: J orge Zahar, 2001.

CARVALHO, Délton Winter. O Direito como um Sistema Social Autopoiético: Auto-Referência, Circularidade e Paradoxos da Teoria e Prática do Direito. Disponível em: <http://www.ihj.org.br/artigos/professores/delton. pdf >. Acesso em: 20 de jul. de 2004.

CARVALHO NETTO, Menelick de. Requisitos pragmáticos da interpretação jurídica sob o paradigma do Estado Democrático de Direito. In: Revista de Direito Comparado. Belo Horizonte. Curso de 
Pós-Graduação em Direito da UFMG e Mandamentos. v. 3. mai./1999. pp. 473-486.

CATTONI DE OLIVEIRA, Marcelo Andrade. Direito Processual Constitucional. Belo Horizonte: Mandamentos, 2001.

CATTONI DE OLIVEIRA, Marcelo Andrade. Devido Processo Legislativo. Belo Horizonte: Mandamentos, 2000.

CHAl, Cássius Guimarães. Descumprimento de Preceito Fundamental: Identidade Constitucional e Vetos à Democracia. Belo Horizonte: Mandamentos, 2004.

CHAMON JÚNIOR, Lúcio Antônio. I mputação e risco no direito penal: lineamentos de uma dogmática em termos de teoria do discurso. Dissertação de Mestrado apresentada à Faculdade de Direito da Universidade Federal de Minas Gerais. Belo Horizonte, 2003.

CHAUÍ, Marilena. Público, Privado, Despotismo. In: NOVAES, Adalto (org. ). Ética. São Paulo: Companhia das Letras, 1992. pp. 345-390.

CORSI, Giancarlo. Sociologia da Constituição. Trad. Juliana Neuenschwander Magalhães. In: Revista da Faculdade de Direito da UFMG. Belo Horizonte. n. 35. jan.-jun./2001. pp. 169-189.

ESTEVES, João Pissara. Nicklas Luhmann - uma apresentação. In: Luhmann, Niklas. A Improbabilidade de Comunicação. Lisboa: Veja, 1993.

GARCÍA, Jesús Ignácio Martinez. Para leer a Luhmann: aviso para juristas. In: LUHMANN, Niklas. El Derecho de la Sociedade. Trad. Javier Torres Nafarrate. México: Universidad IberoAmericana, 2002. (Colección Teoria Social). pp. 13-22.

HABERMAS, Jürgen. A inclusão do outro: estudos de teoria política. Tradução: George Speiber e Paulo Astor Soethe. São Paulo: Loyola, 2002

KELSEN, Hans. Jurisdição Constitucional. Trad. Sérgio Sérvulo da Cunha. São Paulo: Martins Fontes, 2003.

KELSEN, Hans. Teoria Pura do Direito. 6. ed. Trad. João Batista Machado. São Paulo: Martins Fontes, 1999.

LUHMANN, Niklas. El Derecho de la Sociedade. Trad. Javier Torres Nafarrate. México: Universidad IberoAmericana, 2002. (Colección Teoria Social) .

LUHMANN, Niklas. A Constituição como Aquisição Evolutiva. Tradução livre feita por Menelick de Carvalho Netto. (La costituzione come acquisizione evolutiva. In: ZAGREBELSKY, Gustavo (coord.). et alli. II Futuro Della Costituzione. Torino: Einaudi, 1996.).

LUHMANN, Niklas. Legitimação pelo Procedimento. Trad. Maria da conceição Corte-Real. Brasília: Universidade de Brasília, 1980. (Coleção Pensamento Político).

MAGALHÃES, Juliana Neuenschwander. Evolução e Semântica dos Direitos Humanos. Tese de Doutorado apresentada à Università degli Studi di Lecce, Facoltà di Giurisprudenza. Lecci, 2004.

MAGALHÃES, Juliana Neuenschwander. Sobre a Interpretação Jurídica. In: Revista de Direito Comparado. Belo Horizonte: Curso de 
Pós-Graduação em Direito da UFMG e Mandamentos. v. 3. mai./1999. pp. 429-450.

MAUS, Ingeborg. Judiciário como superego da sociedade - o papel da atividade jurisprudencial na "sociedade órfã". Trad. Martônio Lima e Paulo Albuquerque. In: Novos Estudos CEBRAP, $n^{\circ}$ 58, nov./2000. pp. 183-202.

MOUFFE, Chantal. Pensando a Democracia Moderna com e contra Carl Schmitt. Trad. Menelick de Carvalho Netto. In: Caderno da Escola do Legislativo. Belo Horizonte. jul.-dez./1994.

RODRIGUEZ, Dario. Invitación a la Sociologia de Niklas Luhmann. In: LUHMANN, Niklas. El Derecho de la Sociedad. Trad. Javier Torres Nafarrate. México: Universidad IberoAmericana, 2002. (Colección Teoria Social). pp. 23-55.

SCHMITT, Carl. La Defensa de la Constitución. 2. ed. Trad. Manuel Sanchez Sarto. Madrid: Tecnos, 1998.

SCHMITT, Carl. Catolicismo Romano e Forma Política. Lisboa: Hugin, 1998b.

SCHMITT, Carl. Teoría de la Constitución. Madrid: Alianza Universidad, 1996.

\section{NOTAS DE RODAPÉ}

1. Como afirma Chauí (1992:346): “A modernidade, nascida com a Ilustração, teria privilegiado o universal e a racionalidade; teria sido positivista e tecnocêntrica, acreditando no processo linear da civilização, na continuidade temporal da história, em verdades absolutas, no planejamento racional e duradouro da ordem social e política; e teria apostado na padronização dos conhecimentos e da produção econômica como sinais de universalidade".

2. Eram chamados de bárbaros, por não falarem a língua grega, o que os faziam ser vistos como aqueles que falavam bar-bar, isto que balbuciavam, como explica Magalhães (2004).

3. Na visão de Bauman (2001:12): “Os sólidos que estão para ser lançados no cadinho e os que estão derretendo neste momento, o momento da modernidade fluida, são os elos que entrelaçam as escolhas individuais em projetos e ações coletivas - os padrões de comunicação e coordenação entre as políticas de vida conduzidas individualmente, de um lado, e as ações políticas de coletividade humana, de outro".

4. Em sentido coincidente posiciona-se Dario Rodriguez (2002:2829).

5. O Pensamento de Luhmann foi inicialmente influenciado pela Teoria Estruturalista-Funcional de Tacott Parsons, de quem foi aluno no início da década de 60 . “Os seus seminários eram seguidos com enorme interesse por estudantes de todo o mundo, e Luhmann não 
fugiu a regra. Aí nasceu uma afinidade intelectual que podemos hoje considerar a mais consistente do seu pensamento. Se quisermos arriscar uma caracterização geral da proposta de Luhmann, podemos considerá-la na directa continuidade da Sociologia estrutural e funcional de Parsons; isto significa que ele toma essa proposta como ponto de partida, e apenas isso, para desenvolver um modelo intelectual próprio que, em múltiplos aspectos, se afasta da referência original" (ESTEVES, 1993:01). Outra referencia obrigatória de menção são os trabalhos dos biólogos chilenos Humberto Maturana e Francisco Varela, que revolucionaram as Ciências Biológicas com sua Teoria Autopoiética. Através de pesquisas neurofísicas, perceberam que um sistema vivo é dotado de um circuito interno que permite uma interação fechada de seus elementos constituintes, possibilitando sua auto-organização e a auto-produção dos elementos que constituem o mesmo sistema. Com isso, "o sistema interage com seu ambiente, mantendo um processo de acoplamento, através de uma espécie de decodificação das irritações causadas pelo ambiente, efetuadas mediante a utilização de suas próprias interações internas, circularmente organizadas em resposta ao ruído externo (order from noise) e operacionalmente fechado" (CARVALHO, 2003:04).

6. Como destaca o próprio Luhmann, citado por Álvarez (2003:289): "Las investigaciones (de Luhmann) buscan dar paso a un concepto de sociedad radicalmente antihumanístico y radicalmente antiregionalístico. Naturalmente que no se niega que haya hombres y no se ignoran tampoco las grandes diferencias que marcan las condiciones de vida de cada región del globo terrestre. Son investigaciones que renuncian a deducir de estos hechos un criterio para la definición del concepto sociedad y para la determinación de los límites del objeto que corresponde a tal objeto. [...] A los modelos de normas y a los valores que se encuentran en las relaciones entre los individuos se les considera como ideas reguladoras o como componentes del concepto de comunicación".

7. Conforme o próprio Luhmann irá afirmar, citado por Álvarez (2003:303): “El concepto de autoreferencia designa la unidad constitutiva del sistema consigo mismo: unidad de elementos, de procesos, de sistema. 'Consigo mismo' quiere decir independiente del ángulo de observación de otros. El concepto no sólo de fine, sino que también incluye la afirmación de un estado de cosas, ya que sostiene que la unidad sólo pueda llevar a cabo mediante una operación relacionante. En consecuencia, la unidad tiene que efectuarse, y no está dada de antemano como individuo, como sustancia o como idea de la propia operación".

8. Segundo Giancarlo Corsi (2001:173), “o termo 'irritação' é entendido aqui como capacidade de reação a situações ou eventos 
gerados por fatores externos; no nosso caso, basta pensar na legislação como constante fator de irritação do Direito por parte da Política".

9. No caso específico do direito, como mais adiante será mostrado, o código opera por meio da distinção entre direito e não-direito. Alguns autores chegam a firmar que o código jurídico também pode ser identificado como sendo dividido entre lícito e ilícito, como o caso de Lúcio Chamon Jr. (2003).

10. LUHMANN, Niklas. La costituzione come acquisizione evolutiva. In: ZAGREBELSKY, Gustavo (coord.) et alli. II Futuro Della Costituzione. Torino: Einaudi, 1996. Contudo, o presente trabalho fará uso da tradução não oficial produzida pelo Prof. Dr. Menelick de Carvalho Netto para fins didático-pedagógicos em suas aulas de Tópicos em Teoria da Constituição, estando o mesmo disponível aos alunos de Pós-Graduação da Faculdade de Direito da Universidade Federal de Minas Gerais.

11. LUHMANN, Niklas. El Derecho de la Sociedad. Trad. Javier Torres Nafarrate. México: Universidad IberoAmericana, 2002. (Colección Teoria Social).

12. Como esclarece Corsi (2001:173), para “a Constituição, não é colocada a questão do vinculo último ou do fundamento dos ordenamentos jurídicos. Pelo contrário: aqui o Direito é entendido como um sistema social que se vincula e se funda, por si mesmo, de modo contingente (isto é, sem a necessidade de normas externas ou moralmente superiores)".

13. "Do ponto de vista político, a homogeneidade não pode conviver com os sistemas eleitorais liberais, pois ainda que as opiniões sejam acordes, a opinião de centenas de milhares de particulares não é a vontade do povo e nem ao menos a opinião pública. A verdadeira democracia, para Schmitt, é mais que cálculos aritméticos e registro de votos secretos. O conceito de povo vem do direito público e, portanto, o voto melhor exprimiria sua vontade se fosse expresso por aclamação, não de modo secreto. Destarte, o povo aclama um Führer, um exército, o imperador. A democracia direta se funda sobra a aclamação e se contrapõe aos procedimentos da democracia liberal, tais como o voto secreto e a representação parlamentar" (BATISTA, 1999: 178-179, grifos no original).

14. Segundo Arruda (2003:60), Schmitt é famoso por sua posição decisionista, que pode ser subdividir em três formas básicas: a política, como negação da ideai que a política seja uma discussão racional dos indivíduos, para afirmar o conceito de soberania como fundamental; jurídica, como crítica ao legalismo e ao normativismo, para ter compreender que o direito é válido porque sancionado pelo Soberano, não pelo seu conteúdo racional; e moral e teológico, que 
coloca que decisões são as fontes de fundamentação de normas e valores morais.

15. Para maior aprofundamento da questão recomenda-se a leitura de SCHMITT, Catolicismo Romano e Forma Política. Lisboa: Hugin, 1998.

16. Assim, consagrou-se nos Estados Unidos, um modelo difuso da constitucionalidade, no qual as decisões passam por períodos de debates junto aos Tribunais inferiores, sejam eles estaduais ou federais, antes do caso chegar à Suprema Corte.

17. Como bem alerta Ingeborg Maus (2000), a afirmação de superioridade intelectual dos magistrados permitiu, no momento de enfraquecimento dos demais Poderes, que esses assumirem, por transferência, o papel de um superego de um macro sujeito social. Assim, mais que "guardiões" da Constituição, os membros do Tribunal Constitucional se tornaram "guardiões" de tudo o que fosse anterior a constituição, o que incluem compreensões meramente axiológicas. Tal retorno aos valores da nação alemã acaba funcionando como mecanismo de integração da sociedade, que até antes era ocupado pelo Monarca, e que perde sua força com o fortalecimento Parlamento.

18. Todas essas críticas podem hoje ser aplicadas ao pensamento de Robert Alexy, que é tributário a postura adotada pela Corte alemã, em ALEXY, Robert. Teoría de los Derechos Fundamentales. Trad. Ernesto Garzón Valdés. Madrid: Centro de Estudios Constitucionales. 1993, bem como as críticas apresentadas em HABERMAS, Jürgen. A inclusão do outro: estudos de teoria política. Trad. George Speiber e Paulo Astor Soethe. São Paulo: Loyola, 2002.

REVISTA DE DOUTRINA DA 4aㅡ REGIÃO

PUBLICAÇÃO DA ESCOLA DA MAGISTRATURA DO TRF DA 4a REGIÃO

- EMAGIS 